\title{
Photocatalytic self-cleaning coatings for building facade maintenance. Performance analysis through a case-study application
}

\author{
A. Andaloro ${ }^{\text {a,* }}$, E.S. Mazzucchelli ${ }^{\mathrm{a}}$, A. Lucchini $^{\mathrm{a}}$ and M.P. Pedeferri ${ }^{\mathrm{b}}$ \\ a Politecnico di Milano, Department of Architecture, Built Environment and Construction \\ Engineering, Ponzio, Milan, Italy \\ ${ }^{\mathrm{b}}$ Politecnico di Milano, Department of Chemistry, Material and Chemical Engineering \\ "Giulio Natta", Mancinelli, Milan, Italy
}

\begin{abstract}
Facade maintenance has become a key aspect in building management, due the specific actions involved and operation related costs. Within this framework, the application of titanium dioxide photocatalytic sol-gel products on facade elements offers a wide range of opportunities to ensure proper functionality maintenance over time. This paper illustrates the self-cleaning performance of titanium dioxide and silicon dioxide based coatings applied to different kinds of cladding materials. All tested samples were opaque. Preliminary laboratory tests were performed by means of water contact angle measurements to verify hydrophobic and hydrophilic behaviour prior to outdoor application. Afterwards, outdoor tests were performed to monitor colour variation over a 36-month period to verify product effectiveness and durability. Results proved that the application of functionalized nanotechnological coating to a facade can significantly facilitate cleaning operations and reduce the necessary frequency over time. In addition, the output provides some preliminary information about the exposure condition influence on self-cleaning performance, which could be further investigated in the future.
\end{abstract}

Keywords: Facade maintenance, cladding, photocatalysis, self-cleaning coating, retrofit

\section{Introduction}

The constant evolution of facade systems is leading to the use of high performance technology within envelope elements, such as the integration of solar active systems in the form of thermal accumulation or photovoltaic modules for electrical production. However, facade material and component cleaning operations are very often delayed both by owners and facility managers as they involve relevant and frequent investments. It is therefore not unusual that pleasant architectural objects are transformed into soiled surfaces that are unpleasant to witness in the urban context, as shown in Fig. 1. On the other hand, it is clear that the required effort, in terms of water expense, use of detergents, operation cost and time, becomes more constant as soiling deposits on the facade are harsh. Conversely, maintaining the front covers of photovoltaic modules and envelope

\footnotetext{
*Corresponding author: A. Andaloro, Politecnico di Milano, Department of Architecture, Built Environment and Construction Engineering, Via Ponzio 31, 20133, Milan, Italy. Tel.: +39 333 3900052; Fax: +39 02 2399 6080; E-mail: annalisa.andaloro@polimi.it.
} 
surfaces in a clean state is of the outmost importance to ensure that performance levels remain constant over time, and as close as possible to the desired design values.

Polluted operating environments, such as urban or industrial contexts, cause rapid envelope soiling phenomena which in turn raise durability and aesthetic concerns. In this framework, keeping facade materials in a fairly clean condition is fundamental to preserve the proper functionality of the envelope elements over time (Rigone, 2011). For this reason, the integration of Building Maintenance Units (mobile facade access devices moved by electric engine and suspended on ropes or rail, as seen in Fig. 2), referred to as BMU from here on, on the facade is becoming more and more diffused for new buildings.

In fact, their presence optimizes indirect costs due to maintenance operations during the whole building service life, guaranteeing easy and economically convenient access to envelope surfaces. Although BMU's certainly represent a good option, there are some cases where this strategy is not applicable or economically inconvenient, as in the case of existing or new buildings characterized by particularly complex shapes. In these cases, the use of functional self-cleaning coatings can significantly ease cleaning operations due to the combined chemical-physical behaviour of treated surfaces (Diamanti et al., 2013; Watanabe et al., 1999; Yang et al., 2006; Parkin \& Palgrave, 2005; Nishimoto \& Bhushan, 2013).

For example, the photocatalytic activity of titanium dioxide (Miyauchi et al., 2002; Nakajima et al., 2001; Carp et al., 2004) induced by the absorption of ultraviolet (UV) radiation initiates chemical

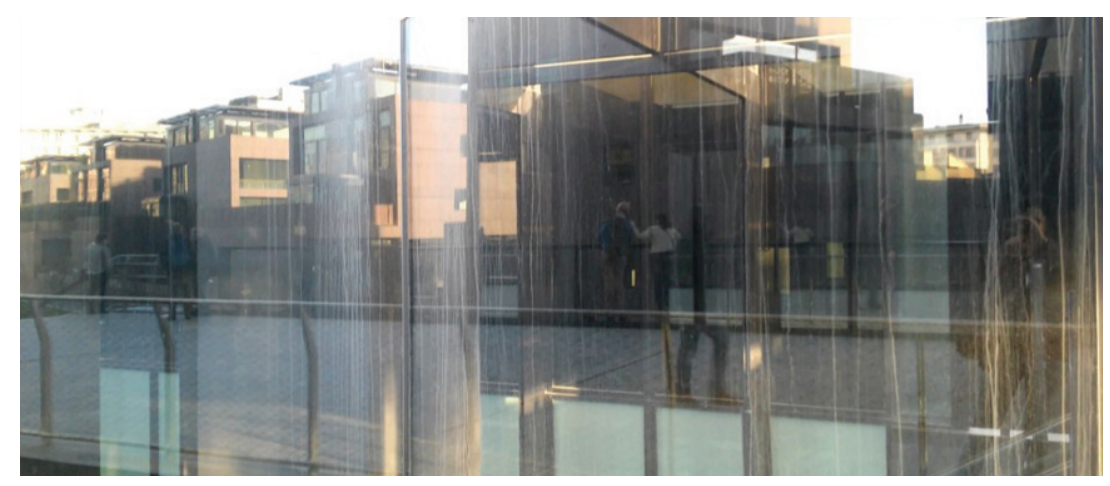

Fig. 1. Example of significant water stains on a facade, caused by lack of maintenance action.

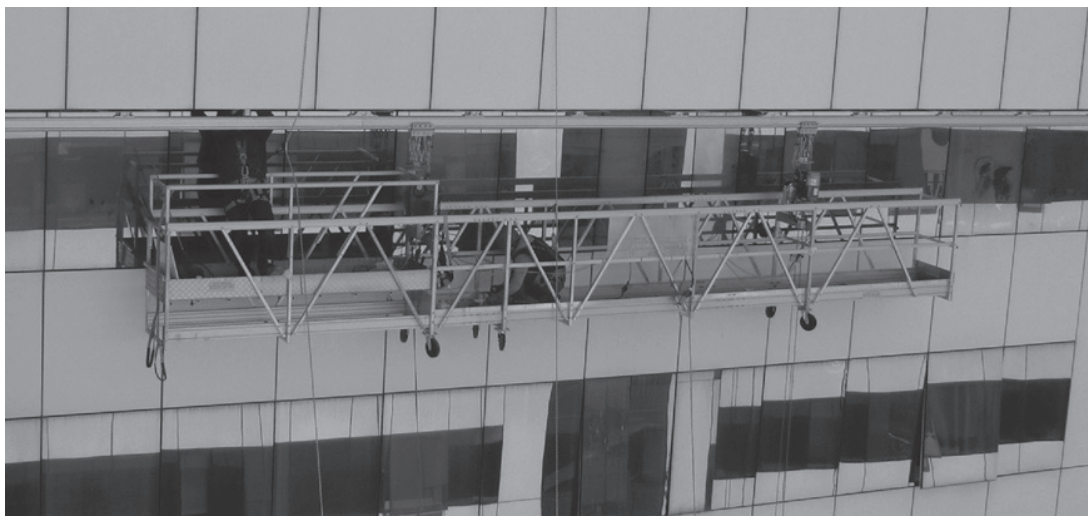

Fig. 2. Building maintenance unit. Source: Rostek. 
oxidation of soiling deposits on exposed surfaces. Afterwards, preliminary decomposition actuated by the coating allows for their easy washing under the effect of driving rain on the building facade, profiting from the UV-induced superhydrophilic state of the surface (Hoffmann et al., 1995; Ganesh et al., 2011; Sciancalepore \& Bondioli, 2015; Fujishima et al., 2001). More in detail, the advantage of the use of photocatalytic coatings is to prevent massive adhesion of dirt deposits, minimizing the necessary cleaning operations in terms of both intensity and frequency (Gladis \& Schumann, 2011). This reduction implies economic benefits for owners and estate managers and on the other hand contributes to a more sustainable management of the built environment. So, the integration of self-cleaning photoactive functional materials is an effective preventive maintenance strategy, that allows consistent savings and reduces environmental impacts of cleaning operations during the whole building service life.

Due to their particular behaviour, titanium dioxide photocatalytic particles have found a wide range of applications in the civil and architectural field over the last decades (Ritter, 2007; Leydecker, 2008; Fernandez, 2006; Chen \& Poon, 2009; Liu et al., 2008).

Over the last 20 years or so, research progress led to the combination of active components such as titanium dioxide photocatalytic nanoparticles with various construction materials such as cement, mortar, asphalt, floor tiles and many others (Chen \& Poon, 2009; Husken et al., 2009), as seen in Figs. 3 and 4. More recently, photocatalytic coatings (paints, plasters or spray transparent coating) to be applied at the end of facade materials production process or on already existing facade surfaces revealed a great potential for air purification and easy cleaning properties (Laufs et al., 2010; Aguia et al., 2010; Maggos et al., 2007; Salthammer \& Fuhrmann, 2007). Titanium dioxide photoactive products are often used for this purpose. These kind of coatings can be applied to a substrate with very simple methods, such as spray or dip-coating (sample immersion in a functionalized liquid solution). This post processing alternative represents a particularly effective way to exploit the quantity of photoactive material used, especially when dealing with opaque cladding materials, where only layers directly exposed to sunlight can be photoactivated and perform photocatalytic behaviour. In fact, catalyst particles eventually dispersed in inner layers cannot play a role in soiling decomposition, air purification and surface self-cleaning if they are not activated by light penetrating inside the material.

In addition to this, self-cleaning materials have found wide acceptance in the field of historical building heritage preservation, due to their transparency on the substrate and the possibility to maintain the original aesthetical appearance of those buildings at almost no effort and very reduced cost (Quagliarini et al., 2012). As a matter of fact, not only does the application of titanium dioxide

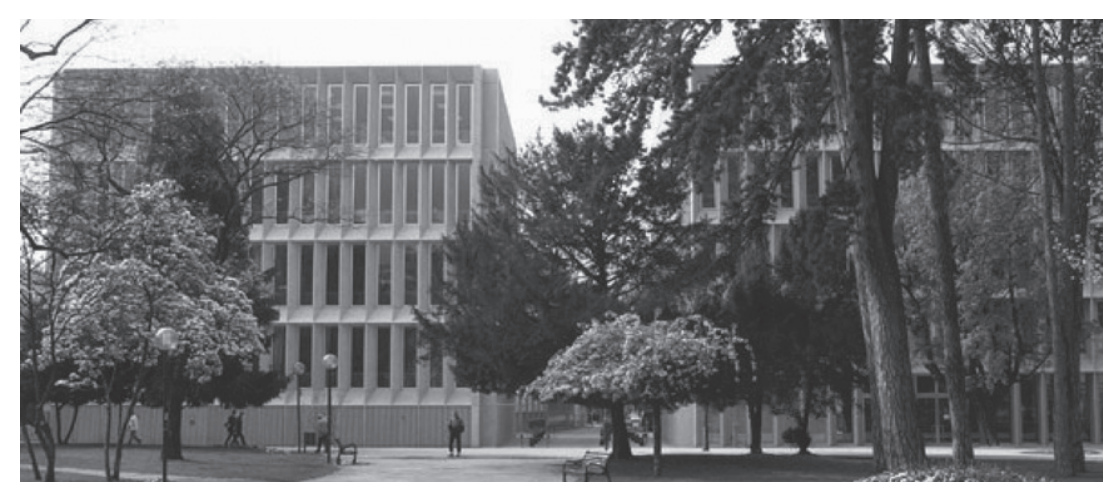

Fig. 3. Cité des Arts et de la Musique, Chambery, France. This is the first building where mortars containing titanium dioxide were applied, 2000 (source: http://citedesarts.chambery.fr/). 


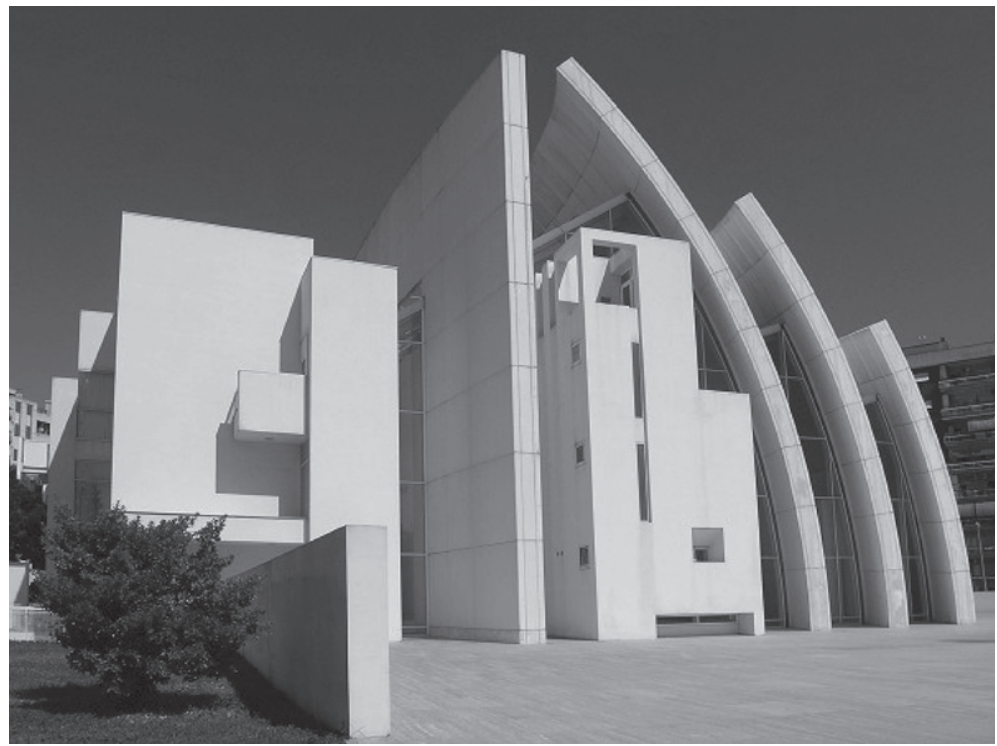

Fig. 4. Church Dives in Misericordia, Rome, Italy designed by architect Richard Meier who choose to build the structure using cement containing a significant percentage of titanium dioxide, 2003 (source: http://files1.structurae.de/).

based products on porous facade materials allow to keep their surface clean over time, but it also minimizes the risk for phototropic bacteria growth, which is usually among the main causes of mould formation related damage in porous cladding materials, both on vertical and horizontal envelope surfaces (roofing) (Graziani et al., 2014).

As a consequence of the aforementioned issues, current research activities on photoactive selfcleaning materials involve not only skills and competences from the chemistry and material science field, but also from the building and construction sector, in order to develop the most appropriate technical solution able to exploit the functionalizing properties of nano-structured materials at the maximum possible level, in case such products are to be applied to building components.

The present work presents the application of titanium dioxide self-cleaning products to different cladding materials. Most of them contain titanium dioxide in the anatase form, that is the molecular structure considered the most active in terms of photocatalytic behaviour over time. In particular, the paper aims at discussing the results of a 36 month-long experiment on cladding materials, and the influence of particularly polluting industrial activities on self-cleaning efficiency over time. The work proposes the integration of such coatings within the building facade as a preventive cleaning strategy which allows to postpone and reduce frequency of ordinary maintenance operations related to facade washing in polluted environments. In the results and discussion section, some considerations concerning coating durability issues are discussed.

\section{Materials and methods}

\subsection{Opaque cladding panels}

Four different materials used for external cladding were tested under normal operating conditions, being installed as external cladding elements (vertical and sub-vertical on a canopy) on an office-industrial building located in Northern Italy (see Fig. 5). 
All the materials tested outdoors were part of an existing building facade and could therefore not be removed for laboratory analysis. All the work performed on these elements had to be carried out in situ. The main characteristics of the four materials are summarized in Table 1. Samples of the same materials were also subjected to laboratory tests aimed at verifying surface hydrophilic or hydrophobic behaviour prior to outdoor self-cleaning coating applications. Such tests involved the use of a UV-lamp for sample irradiation and measurement of the water contact angle over time, as detailed in section 2.3 . The main characteristics of the tested specimen are included in Table 1.

\subsection{Deposition of titanium dioxide sol-gel products for surface self-cleaning}

The materials were treated with three different functionalizing products and with a combination of two out of the three. All the self-cleaning products used for the experimental campaign were produced through sol-gel processing - a very versatile method to produce photoactive sols. A sol is a dispersion of colloidal particles in a liquid, titanium or silicon dioxide in the specific case. After product application, solvent evaporation initiates the creation of a photoactive gel, that is to say an interconnected network of active particles characterized by porosity magnitude below one

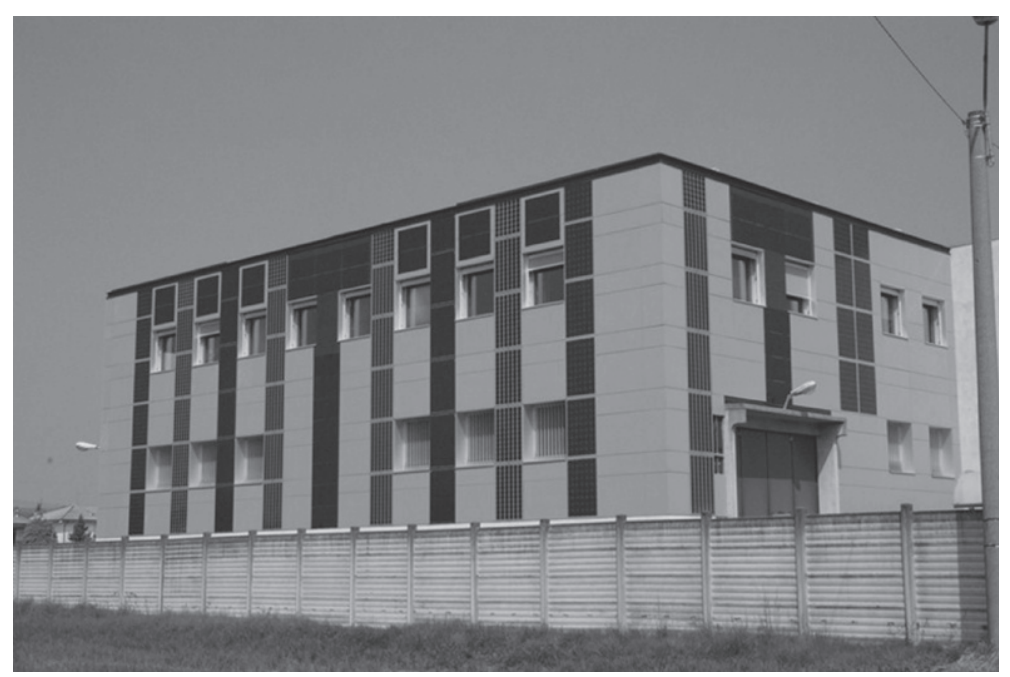

Fig. 5. View of the case study building. Source: www.edilportale.com.

Table 1

Tested cladding panels: main characteristics and exposure condition (outdoor refers to in situ exposure, laboratory refers to the procedure described in section 2.3)

\begin{tabular}{lllll}
\hline Product name and producer & Short name & Material & Colour & Test condition \\
\hline Esoroccia - MMG srl & CE & Granite powder and cement & Grey & Outdoor \\
Collection - Laminam & LY/LW & Laminated porcelain & Yellow/White & Outdoor/Lab \\
Silbonit HA-HC - SIL & SC-V & Silica-calcium & Yellow & Outdoor vertical \\
Silbonit HA-HC - SIL & SC-C & Silica-calcium & Yellow & Outdoor canopy \\
Cotto rdb - RDB SpA & CO & Terracotta tile & Red & Outdoor \\
Cotto - Unieco Bologna & CL & Terracotta tile & Red & Laboratory \\
\hline
\end{tabular}


micrometre, and polymeric chains with length above one micrometre. All products are commercially available, and the dimension of colloidal particles dispersed in the solutions ranges between 10-100 nm (Hench \& West, 1990). For each cladding material, reference non-treated samples have been kept under constant monitoring to highlight substantial differences in soiling intensity. Product compositions and their functional characteristics are briefly summarized in Table 2.

Sol $111 \mathrm{CD}(\mathrm{T})$ is a semi-transparent water based solution. The active photo catalyst is nanocristalline titanium dioxide, and its use is recommended to provide self-cleaning properties to building components, cladding panels and even furniture elements. As the suggested deposition thickness is really limited to maintain film transparency, this product should rather be applied at the end of the production processes as consistent mechanical stress can damage coating photoactive behaviour.

Sol 232/OX (S1) is a semi-transparent isopropyl alcohol based solution. The active component is nanocristalline silicon dioxide, and its application gives a strongly hydrophobic characteristic to the treated surface (Lakshmi, 2011). This means that the material surface is unlikely to be wet even in case of driving rain or direct water pouring, similarly to what happens in the case of more traditional siloxane based hydrophobic treatments. However, in this case the hydrophobic surface behaviour is based not only on chemical but also morphologic characteristics. In fact, the dried coating does not form a completely smooth surface. On the contrary, it is characterized by the presence of numerous peaks and narrow valleys which prevent water droplets to infiltrate. For this reason, wettability of the treated surface is extremely reduced. Effects of such modified behaviour are shown in section 3.1.

Sol 322/OX (S2) is an isopropyl alcohol based solution containing suspended silicon dioxide nanoparticles. This product gives surfaces water-repellent characteristics through the so called lotus effect.

Sol $111 C D+$ Sol 322/OX (T+S2) represents a combination of the two sols, applied one above the other providing the necessary time frame for surface drying.

The deposition method used for this experimental set-up was a spraying technique. Sol mixtures were produced from titanium and silicon with a hydrolysis and condensation process to form the final self-cleaning products (Hench \& West, 1990). When the liquid solution is applied to a surface, a film forms and the subsequent drying (in natural or accelerated conditions) allows for enhanced mechanical resistance of the coating. All of the above mentioned solutions are completely transparent to the human eye after the solvent evaporation process is completed, both in wet and dry condition of the substrate. This feature is very important from an application related viewpoint as it broadens the possibility of self-cleaning product use both in new construction and historic buildings (Quagliarini et al., 2012).

Table 2

Chemical base element of the tested sol-gel products and specific functional properties

\begin{tabular}{lcll}
\hline Product name & Short name & Chemical base & Functional property \\
\hline Sol $111 \mathrm{CD}$ & $\mathrm{T}$ & $\begin{array}{c}\mathrm{TiO}_{2} \\
\text { silica 1-2\% and functionalized }\end{array}$ & $\begin{array}{l}\text { Photocatalytic and hydrophilic } \\
\text { Sol 232/OX }\end{array}$ \\
Sol 322/OX & $\mathrm{S} 1$ & $\mathrm{SiO}_{2}$ & Hydrophobic \\
Sol 111 CD + Sol 322/OX & $\mathrm{S} 2$ & $\mathrm{SiO}_{2}$ & $\begin{array}{l}\text { Water repellent (Lotus effect) } \\
\end{array}$ \\
& $\mathrm{T}+\mathrm{S} 2$ & $\begin{array}{c}\text { Application of two different } \\
\text { sprays, one above the }\end{array}$ & Strongly hydrophobic \\
& & other & \\
& & &
\end{tabular}




\subsection{Laboratory verification of hydrophilic and hydrophobic properties}

Four different samples treated with the self-cleaning coatings and a non-treated reference specimen were tested to verify the achievement of the desired functionalizing surface properties. The substrate chosen for this preliminary laboratory test was the Laminam LY (see Table 1) and the four applied products are those listed in Table 2. The test method is based on the water contact angle (WCA) variation observation through 4 hours of continued UV irradiation, according to what is proposed in the ISO 27448 standard. Figure 6 shows an example of WCA measurement of one of the tested samples.

The initial contact angle value was determined on fifteen discreet points for each test specimen as suggested in the UNI EN 15802 : 2009 standard, and an average value was calculated. Afterwards, the UV source was activated and an ultraviolet light radiometer was used to set the irradiation intensity to $2 \mathrm{~mW} / \mathrm{cm}^{2}$ (tolerance $0.1 \mathrm{~mW}$ ). The water contact angle measurement was repeated every hour for the five different points of each specimen, with the last measurement after 4 hours of continued UV irradiation. All values were noted in a log book, until the required conditions for the determination of a final contact angle according to the applied test procedure (standard deviation of three consecutive measurements on a specimen lower than $10 \%$ ) were achieved.

\subsection{Outdoor exposure test}

An outdoor experimental activity was carried out on an existing building located in Turate (Como), Northern Italy. The different cladding materials listed in Table 1 were treated with the sol product varieties described in section 2.2 and listed in Table 2, and their self-cleaning performance was monitored over 36 months. Sols were applied with pressurized spray coating techniques as shown in Fig. 7a-b.

For each selected material substrate (see Table 1), a non-treated specimen was monitored with the same testing procedure, and maintained as a reference. The parameter used to estimate selfcleaning performance is colour variation measured on opaque cladding elements. This has been performed taking sample colour coordinates on two, four or eight different points for each cladding element depending on the element size (see Fig. 8) from which an average value was determined.

For the purpose of this study, measurements were taken 5-10 cm away from elements borders, in order to avoid biased results due to border effects or to a relative closeness of joints between adjacent cladding panels. This technique was the only means to monitor self-cleaning performance of the cladding elements over time, as it was not possible to remove the facade panels for further laboratory analyses. However, the authors relied on results from previous works on photoactive self-cleaning products, proposing colorimetry as an accountable method for the estimation of self-cleaning capacity when operating outdoors (Quagliarini et al., 2012; Graziani et al., 2014;

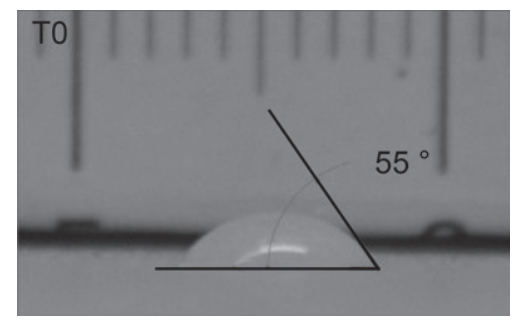

Fig. 6. Water contact angle measurement just after drop pouring. The image is shadowed as the picture was taken before UV irradiation source activation. 


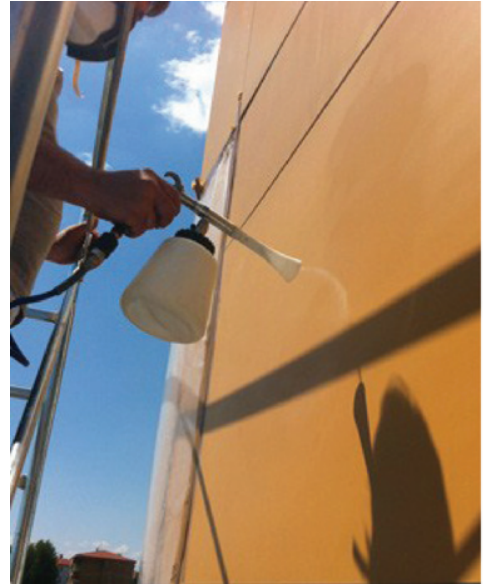

(a)

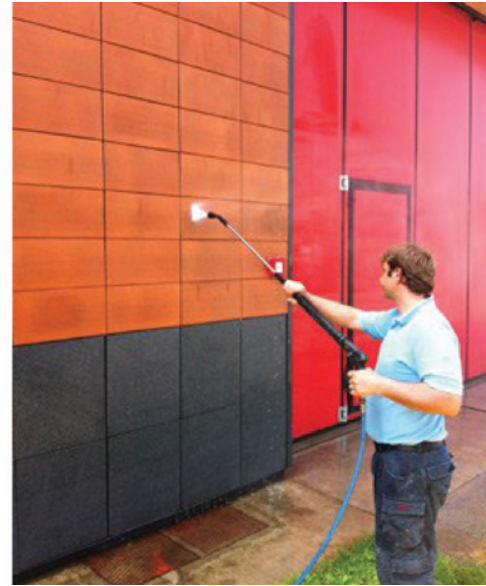

(b)

Fig. 7a-b. Pressurized spray coating on facade cladding panels.

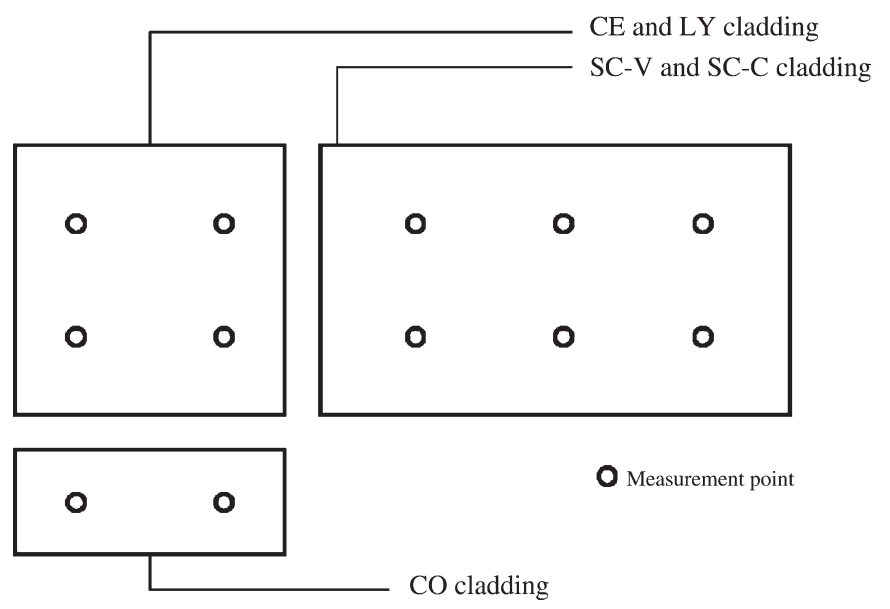

Fig. 8. Scheme of measurement points on cladding elements.

Gladis \& Schumann, 2011). Colour parameters were extracted by means of a portable KonicaMinolta spectrophotometer CM-2600d, which measures surface spectral reflectance every $10 \mathrm{~nm}$ in the range of $360-740 \mathrm{~nm}$, using the supporting software Spectramagic NX. From reflectance data collected on sample surfaces, the instrument calculates colour coordinates according to the CIElab standards, $L^{*}$ - brightness, $a^{*}$ - hues from red to green and $b^{*}$ - hues from yellow to blue. Colour variation over time $\Delta E$ was calculated according to the following formula, which measures the difference between two points in the CIElab colour space, respectively corresponding to the surface colour at time $t$ (measurement during outdoor weathering) and the same surface initial colour $t_{0}$ measured after sol-gel application and drying (Equation (1)):

$$
\Delta E=\sqrt{\left(L_{t}^{*}-L_{0}^{*}\right)^{2}+\left(a_{t}^{*}-a_{0}^{*}\right)^{2}+\left(b_{t}^{*}-b_{0}^{*}\right)^{2}}
$$

For each cladding element, six measurements were performed during the outdoor testing period. As the humidity content influences materials reflectance, preliminary laboratory tests were carried out to identify a repeatable colour measurement strategy to be applied for all of the outdoor 
experimental activities. Laminated porcelain samples were wetted according to two modes: driving rain simulation or total water immersion. In the first case, rain was simulated keeping samples under a continuous water stream for 4 hours. In the latter, samples were kept inside water for 2 days. Colour variation measurements were performed according to Equation 1 to benchmark materials drying duration (dry sample has $\Delta E \approx 0$ ).

\section{Results and discussion}

\subsection{Laboratory tests}

During 4 hours of UV irradiation, WCA values for the tested samples varied as shown in Table 3. The table also shows that the treated samples showed different surface behaviour even before the UV irradiation test started, which was hydrophilic in the case of Sol T and hydrophobic in the case of Sol S1, Sol S2 and the combination of Sol T+S2. This happened because the applied sol products immediately provided treated surfaces with the desired characteristics, which occurred prior to actual start of the irradiation test (Graziani et al., 2014). However, laboratory performed water contact angle tests showed a consistent enhancement of these properties under the effect of UV light, after a stabilization time interval which was necessary to complete the photo activation of the treated surface, as also required in the ISO 27448 standard.

As expected, the non-treated reference specimen $(\mathrm{N})$ did not show significant WCA alterations with UV light irradiation. Sample T, which was treated with titanium dioxide showed hydrophilic surface behaviour from the beginning of the test onward and had a consistent decrease of the water contact angle after the 4 hour UV irradiation time. However, this trend showed up after the second hour of UV irradiation, while it was opposite during the first hour. This may be ascribed to a buffering time during which the photo catalyst goes through the photo activation process. Samples S1 and S2 were both treated with different silicon dioxide based sols and showed a rather hydrophobic behaviour, as expected. The last analysed specimen was coated with a combination of two sols: T and S2. The results of this last application are particularly relevant as the global results leads to a strongly hydrophobic surface behaviour, showing a water contact angle which is up to $30^{\circ}$ higher than the mere hydrophobic surfaces of samples S1 and S2 after 4 hours of UV irradiation. The above mentioned strongly hydrophobic behaviour is caused by the combination of hydrophobic and photocatalytic surface properties provided by titanium and silicon dioxide (Boroujeny et al., 2012). This can be particularly relevant for certain outdoor applications, when this behaviour could be more suitable to maintain facade surfaces in a clean condition according to specific operating environments. In fact, soiling deposits are very unlikely to stick onto the surface of hydrophobic

Table 3

Water contact angle measurements for the different treated samples (4 hours UV irradiation test). Only the average values of the measurements made for each sample are reported in this table

\begin{tabular}{|c|c|c|c|c|c|}
\hline \multicolumn{6}{|c|}{ Water contact angle measurement (degrees) } \\
\hline Irradiation time & Non treated $(\mathrm{N})$ & Sol $111 \mathrm{CD}(\mathrm{T})$ & Sol 232/OX (S1) & Sol 322/OX (S2) & $\begin{array}{c}\text { Sol } 111 \mathrm{CD}+ \\
\text { Sol 322/OX }(\mathrm{T}+\mathrm{S} 2)\end{array}$ \\
\hline $\mathrm{Oh}$ - dark & $55[$ st.dev $=0.078]$ & $39[$ st.dev $=0.073]$ & $96[$ st.dev $=0.078]$ & $84[$ st.dev $=0.076]$ & $99[$ st.dev $=0.078]$ \\
\hline $1 \mathrm{~h}$ & $54[$ st.dev $=0.076]$ & $48[$ st.dev $=0.080]$ & $81[$ st.dev $=0.080]$ & $74[$ st.dev $=0.078]$ & $96[$ st.dev $=0.076]$ \\
\hline $2 \mathrm{~h}$ & $58[$ st.dev $=0.078]$ & $44[$ st.dev $=0.082]$ & $90[$ st.dev $=0.083]$ & $87[$ st.dev $=0.089]$ & $90[$ st.dev $=0.089]$ \\
\hline $4 \mathrm{~h}$ & $66[$ st.dev $=0.077]$ & $28[$ st.dev $=0.090]$ & $93[$ st.dev $=0.084]$ & $87[$ st.dev $=0.088]$ & $118[$ st.dev $=0.079]$ \\
\hline
\end{tabular}


materials, opposite from what happens with superhydrophilic materials. So, in the latter case rain events are necessary to pursue natural facade washing (Ballari \& Brouwers, 2013). Conversely, in the former case the coated area could remain clean for longer periods without any need for rain. Of course, real and forecasted operating condition and environmental context should be carefully evaluated before choosing a specific surface treatment.

As previously shown in Table 3, the five different samples showed dramatically different wettability even before UV irradiation test initiation (Graziani et al., 2014). This proves that surface treatments convey a specific behaviour to treated surfaces since the moment of their first application. Despite surface functional properties are increased by solar light activation, the preliminary surface state is useful to prevent soiling deposits on the surface (especially in the case of hydrophobic and strongly hydrophobic behaviour).

\subsection{Outdoor photocatalytic efficiency measurements}

The self-cleaning performance of applied coatings was measured through a prolonged monitoring of colour coordinates variation for each tested cladding material and type of coating. The measurements were repeated 6 times during 24 months. As an example, Fig. 9a-b shows colour coordinates variation on both elevation North and South of the tested building, located in the area of Como (Italy) for one of the sample cladding. This technique was chosen as it could be easily performed without the need of dismantling facade cladding to bring it to a laboratory facility, which was of course not possible in this case (working on an already existing building). Moreover, monitoring $\Delta \mathrm{E}$ values on an outdoor experimental campaign has already been proved to be an effective way to evaluate the self-cleaning performance of the applied coatings (Quagliarini et al., 2012; Graziani et al., 2014; Gladis \& Schumann, 2011).

Cement cladding elements (CE) had higher $\Delta \mathrm{E}$ and $\Delta \mathrm{L}^{*}$ values on the Northern exposure over time on average as compared to the Southern elevation (meaning that they had heavier soiling deposits on their surface). Hydrophobic coatings S1 and S2 showed lower colour variation than the photocatalytic ones. In addition, non-treated samples showed a better behaviour than coated cladding elements on this exposure, so it is easy to infer that there is no benefit in integrating selfcleaning coating for the Northern orientation of facades in the case of cement cladding elements.

Global $\Delta \mathrm{E}$ values are significantly lower on the Southern facade, and this could be partly ascribed to the presence of direct sunlight irradiation, which enhances the photocatalytic activity of coatings containing $\mathrm{TiO}_{2}$ (Maggos et al., 2007). Panels treated with Sol T registered higher $\Delta \mathrm{E}$ values on

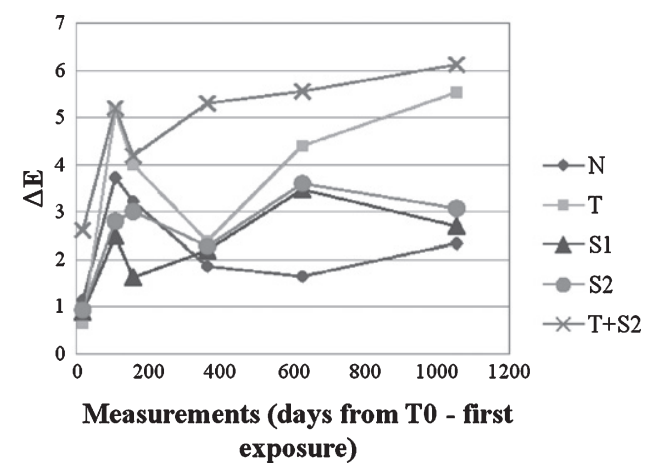

(a)

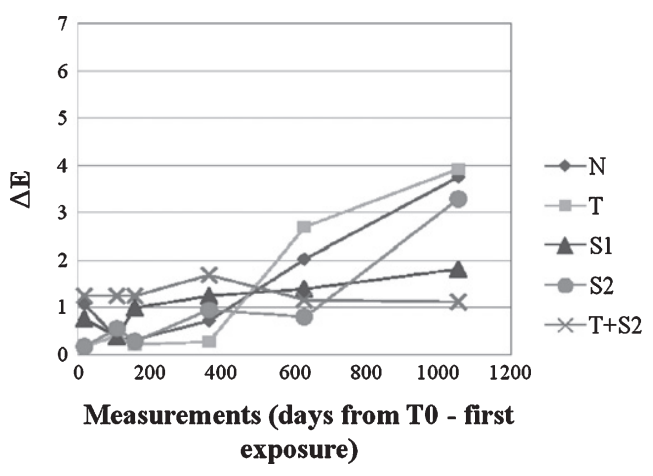

(b)

Fig. 9a-b. $\Delta \mathrm{E}$ variation for CE cladding elements (Left: Northern elevation, Right: Southern elevation). 
the last measurement day, while samples treated with Sol T+S2 registered extremely low colour variation, and the $\Delta \mathrm{E}$ value registered is quite similar to the original one at time $t_{0}$. This reveals actual soiling affecting the non-treated material, as opposed to the negligible accumulation of darkening particles (such as organic pollutants and particulate matter) on surfaces coated with photoactive $\mathrm{TiO}_{2}$ sol-gel (Sol T and $\mathrm{T}+\mathrm{S} 2$ ). This implies that the application of self-cleaning coatings is much more effective in the case of Southern exposure. A supporting explanation for this result is related to the presence of direct light irradiation on this latter orientation, conversely to what happens on the Northern side of the building. In fact, it has been proven that the photocatalytic activity of titanium dioxide is higher under the effect of direct exposure to light (Watanabe et al., 1999), implying a higher soiling decomposition rate and stronger self-cleaning capability.

Parameters having an influence on the self-cleaning performance can be related to higher direct rainfall or generally more favourable weather conditions (e.g. dominant wind direction, relative humidity values and the presence of direct solar irradiation) (Ballari \& Brouwers, 2013; Moussiopoulos et al., 2008; Maggos et al., 2007). Further analysis on prevalent wind direction during rain events could be performed in the future to determine the influence of wind driven rain on a specific elevation on the global self-cleaning performance.

A brief comparison among all tested materials is proposed, for the purpose of evaluating the influence of specific cladding material on global self-cleaning efficiency, summarizing the results of outdoor exposure tests according to the two tested orientations, North and South. The graphs in the two figures show a global view of the $\Delta \mathrm{E}$ values on the last day of measurements according to treated substrate and sorted by coating type. As far as the Northern facade is concerned (Fig. 10a), Sol $T$ has shown low $\Delta E$ values on all tested substrates, except for terracotta cladding elements (CO) which have reported a higher variation. The combined Sol T+S2 has proved its efficiency on cement based (CE) cladding panels and performed quite well also on Silica calcium vertical panels SC-V, but according to test results it is less suitable in the case of terracotta cladding panels (CO), where Sol S1 showed better performance (Fig. 10a). However, the hydrophobic coating had a good self-cleaning performance in just one single case, while photocatalytic coatings generally tend to perform better than hydrophobic products in the discussed results. Figure $10 \mathrm{~b}$ summarizes final colour variation results for the Southern elevation. In this case, photoactive materials have shown a satisfactory self-cleaning ability both for cement based materials (CE) and laminated porcelain (LY). In fact, Sol T and Sol T+S2 were the most performing coatings in terms of self-cleaning activity in both cases (lowest $\Delta E$ values). Results for the Southern facade shown in Fig. 10b suggest that facade materials generally benefit from direct sunlight exposure when treated with functional coatings.

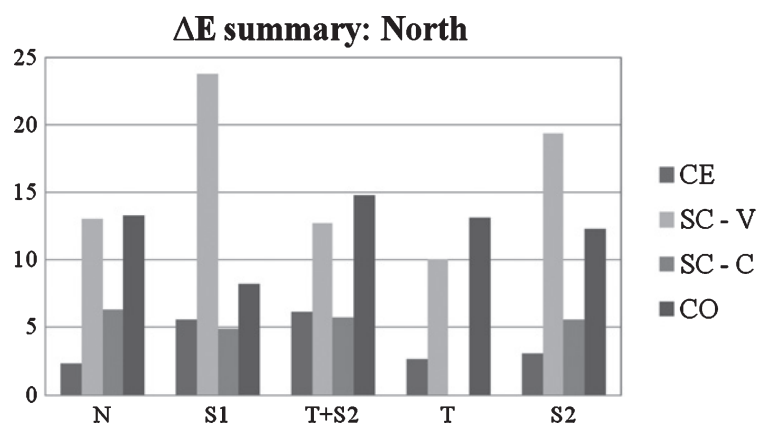

(a)

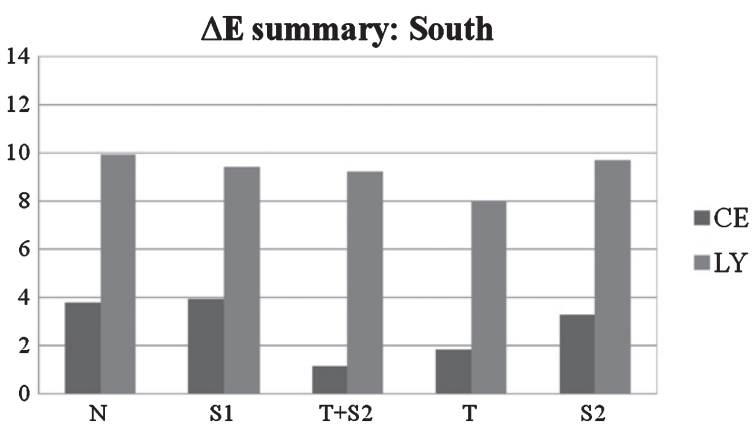

(b)

Fig. 10a-b. Summary of $\Delta E$ values reported on tested materials (a: North, b: South) according to material substrate and applied coatings on the last measurement day (namely end of the monitoring period for the scope of this work). 


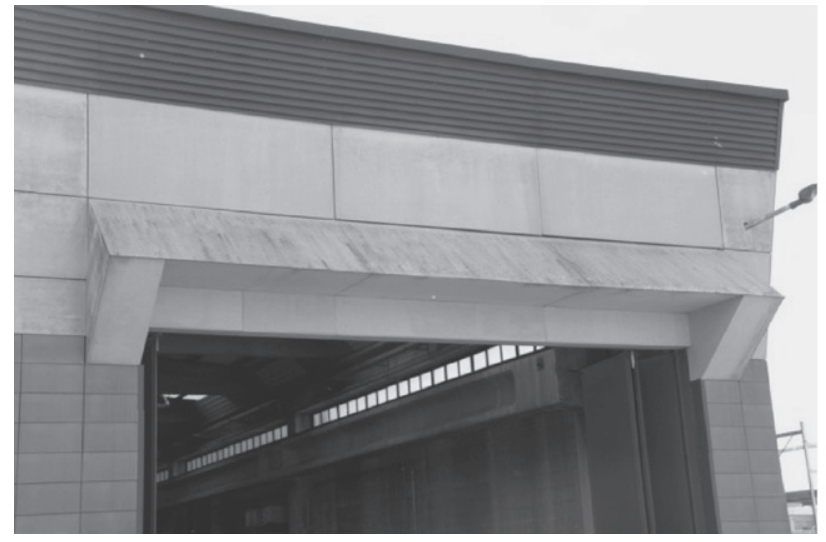

(a)

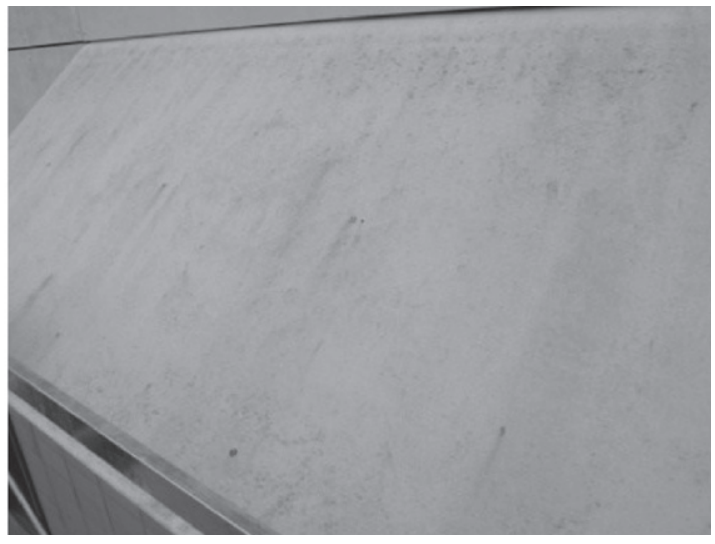

(b)

Fig. 11a-b. Heavy soiling deposits on the protection canopy (silica-calcium cladding).

In addition to this, a quick comparison between the $\Delta \mathrm{E}$ values measured on Southern and Northern facades for the same coating (Sol T) on cement substrates (CE) gives evidence of the fact that the photocatalytic coating (Sol T) has a greater self-cleaning efficiency on the Southern exposure (see Fig. 10a-b). In fact, on a Northern elevation, less sunlight reaches the material surface compared to other orientations. Under this condition, the titanium dioxide needs more time to complete its photo activation (Maggos et al., 2007), which makes the presence of the coating less efficient as compared to the same application on a Southern facade.

One last note concerns silica-calcium cladding elements located on the sub-vertical canopy (SCC) which showed satisfying self-cleaning behaviour during the first operating period (12 months approximately), but at the time of the last two colour measurements had soiling deposits clearly visible and spread all over the cladding surface, as shown in Fig. 11a-b.

Further analyses could be done in the future to verify the causes of the limited service life of coatings in this case, as many different alternatives are possible. However, it is possible to state that the reduction in self-cleaning performance is not related to coating ageing, as the rest of the Northern facade did not show significant soiling deposits. As a matter of fact, the canopy location is likely to have had an influence on soiling deposit persistence, as it receives consistent amounts of thin iron powders rising upward from the production site underneath. These may have caused precocious decay in self-cleaning performance due to titanium dioxide removal from the surface, caused by mechanical abrasion in combination with weather agents (especially wind, but also rain) This fact raises some concerns related to coating durability issues, discussed by Hassan et al., 2010; Osborn et al., 2014; Mellot et al., 2006; Graziani et al., 2014.

\section{Conclusion}

The contemporary trend towards a more sustainable management of the built environment suggests the integration of self-cleaning coatings on facades as a viable option for enhanced cleaning capabilities of external surfaces. This possibility becomes even more relevant if taking into account the increasingly frequent inclusion of solar active components in facade systems, which require their front covers to remain as clean as possible in order to guarantee performance design levels. 
This article focused on the self-cleaning behaviour of different opaque envelope materials coated with titanium dioxide based sol-gel products, proposing a convenient and effective alternative to traditional facade washing for maintenance purposes. Further research work has also been carried forward regarding the application of the same self-cleaning product to glass, but results are not presented in this article for the sake of simplicity. A comparison with hydrophobic silicon dioxide based surface treatments was conducted in order to determine specific convenience conditions according to the different cladding element materials. Both laboratory experimental techniques and an outdoor weathering set-up were used to evaluate self-cleaning coatings performances. More specifically, laboratory wettability tests were performed and an extensive colour variation monitoring campaign was carried out on an existing building for 36 months.

At a first laboratory characterization, titanium dioxide based sol showed hydrophilic characteristics, while both the two silicon dioxide based products were hydrophobic. In addition, the combination of titanium and silicon dioxide provided coated surfaces with strong hydrophobicity. This condition may be particularly advantageous in significantly polluted environments with low precipitation rates, where the ordinary self-cleaning of facades through rainfall washing can hardly be achieved. Within the scope of this work, outdoor exposure tests outlined differences between Northern and Southern exposures. The differences can be ascribed to the presence of direct irradiation in the latter case, which is likely to enhance photocatalytic reaction speed and consequently ease spontaneous cleaning during rain events. This suggests that the application of titanium dioxide based self-cleaning coatings is more effective when coupled with the most suitable orientation of a facade. Sol T showed significantly high self-cleaning performance on tested cladding materials, such as cement, terracotta and laminated composites, providing very limited colour variations at the end of the monitoring period; mixing a titanium dioxide based sol with silica also allowed to achieve satisfying levels of cleanliness at the end of the monitoring period. Finally, some durability concerns on retrofitting coating application have arisen due to the visible soiling deposits on the silica calcium cladding panels located on the Northern facade. In this case, the self-cleaning performance was satisfying during the first 12 months but after this period dark stains started to build up on the surface.

Considering all of the above, the use of self-cleaning coatings on facade surfaces enables owners and designers to act in the direction of maintenance cost reduction in the medium and long-term. So, further research effort in the near future will be dedicated to the investigation of self-cleaning coating compatibility with transparent and active facade components. In addition to this, more detailed climatic analysis within the context of performed experiments could provide interesting insights in triggering causes for limited service life or efficiency for more effective product development on the side of tuning material properties.

\section{Acknowledgments}

The authors thank Nextmaterials s.r.l. for supplying the nanostructured titanium and silicon dioxide sols and Aderma s.r.l. for participating in the experiments providing free access to the company building, which was used as a case study.

\section{References}

Aguia, C., Angelo, J., Madeira, L. M., \& Mendes, A. (2010). Influence of Photocatalytic Paint Components on the Photoactivity of P25 Towards NO Abatement. Catalysis Today, 151(1-2), 77-83. 
Ballari, M. M., \& Brouwers H. J. H. (2013). Full scale demonstration of air-purifying pavement. Journal of Hazardous Materials, 254, 406-414.

Beldeens, A. (2006). Environmental Friendly Concrete Pavement Blocks: Air Purification In The Centre Of Antwerp. Proceedings of the 8th International Conference on Concrete Block Paving, San Francisco, California, USA.

Boroujeny, B. S., Afshar, A., \& Dolati, A. (2012). Photoactive and self-cleaning TiO2-SiO2 thin films on 316L stainless steel. Thin Solid Films, 520(20), 6355-6360.

Carp, O., Huisman, C. L., \& Reller, A. (2004). Photoinduced reactivity of titanium dioxide. Progress in Solid State Chemistry, 32(1-2), 33-177.

Chen, J., \& Poon, C. S. (2009). Photocatalytic construction and building materials: From fundamentals to applications. Building and Environment, 44(9), 1899-1906.

Chen, J., \& Poon, C. S. (2009). Environmental photocatalytic cementitious materials: Influence of the microstructure of cement paste on photocatalytic pollution degradation. Environmental Science \& Technology, 43(23), 8948-8952.

Diamanti, M. V., Del Curto, B., Ormellese, M., \& Pedeferri, M. P. (2013). Photocatalytic and self-cleaning activity of colored mortars containing TiO2. Construction and Building Materials, 46, 167-174.

Fernandez, J. E. (2006). Material Architecture: Emergent materials and issues for innovative and responsible buildings. Elsevier Architectural Press.

Fujishima, A., Rao, T. N., \& Tryk, D. A. (2000). Titanium dioxide photocatalyisis. Journal of Photochemistry and Photobiology C: Photochemistry Reviews, 1(1), 1-21.

Ganesh, V. A., Raut, H. K., Nair, A. S., \& Ramakrishna, S. (2011). A review on self-cleaning coatings Journal of Materials Chemistry, 21, 16304-16322.

Gladis, F., \& Schumann, R. (2011). Influence of material properties and photocatalysis on phototrophic growth in multi-year roof weathering. International Biodeterioration \& Biodegradation, 65(1), 36-44.

Graziani, L., Quagliarini, E., Bondioli, F., \& D’Orazio, M. (2014). Durability of self-cleaning TiO2 coatings on fired clay brick facades: Effects of UV exposure and wet \& dry cycles. Building and Environment, 71, 193-203.

Graziani, L., Quagliarini, E., Osimani, A., Aquilanti, L., Clementi, F., \& D'Orazio, M. (2014). The influence of clay brick substratum on the inhibitory efficiency of TiO2 nanocoating against biofouling. Building and Environment, 82, 128-134.

Hassan, M. M., Dylla, H., Mohammad, L. N., \& Rupnow, T. (2010). Evaluation of the durability of titanium dioxide photocatalyst coating for concrete pavement. Construction and Building Materials, 24, 1456-1461.

Hench, L. L., \& West, J. K. (1990). The sol-gel process. Chemical Reviews, 90, 33-72.

Hoffmann, M. R., Martin, S. T., Choi, W., \& Bahnemannt, D. W. (1995). Environmental application of semiconductor photocatalysis. Chemical Reviews, 95, 69-96.

Husken, G., Hunger, M., \& Brouwers, H. (2009). Experimental study of photocatalytic concrete products for air purification. Building and Environment, 44, 2463-2474.

ISO 27448:2009 (2009). Fine ceramics (advanced ceramics, advanced technical ceramics) - Test method for self-cleaning performance of semiconducting photocatalytic materials - Measurement of water contact angle.

Lakshmi, R. V., Bharathidasan, T., \& Basu, B. J. (2011). Superhydrophobic sol-gel nanocomposite coatings with enhanced hardness. Applied Surface Science, 257, 10421-10426.

Laufs, S., Burgeth, G., Duttlinger, W., Kurtenbach, R., Maban, M., Thomas, C., Wiesen, P., \& Kleffmann, J. (2010). Conversion of nitrogen oxides on commercial photocatalytic dispersion paints. Atmospheric Environment, 44, 2341-2349.

Leydecker, S. (2008). Nanomaterials in Architecture, Interior Architecture and Design, Springer Science \& Business Media.

Liu, Z., Zhang, X., Murakami, T., \& Fujishima, A. (2008). Sol-gel $\mathrm{SiO}_{2} / \mathrm{TiO}_{2}$ bilayer films with self-cleaning and antireflection properties. Solar Energy Mater Solar Cells, 92, 1434-1438.

Maggos, T., Bartzis, J. G., Liakou, M., \& Gobin, C. (2007). Photocatalytic degradation of NOx gases using TiO2-containing paint: A real scale study. Journal of Hazardous Materials, 146, 668-673.

Mellott, N. P., Durucan, C., Pantano, C. G., \& Guglielmi, M. (2006). Commercial and laboratory prepared titanium dioxide thin films for self-cleaning glasses: Photocatalytic performance and chemical durability. Thin Solid Films, 502, 112-120.

Miyauchi, M., Kieda, N., Hishita, S., Takefumi, M., Nakajima, A., Watanabe, T., \& Hashimoto, K. (2005). Reversible wettability control of TiO2 surface by light irradiation. Surface Science, 511, 401-407.

Moussiopoulos, N., Barmpas, P. H., Ossanlis, I., \& Bartzis, J. (2008). Comparison of numerical and experimental results for the evaluation of the depollution effectiveness of photocatalytic coverings in street canyons. Environmental Modeling \& Assessment, 13, 357-368.

Nakajima, A., Koizumi, S., Watanabe, T., \& Hashimoto, K. (2001). Effect of repeated photo-illumination on the wettability conversion of titanium dioxide. Journal of Photochemistry and Photobiology A: Chemistry, 146, 129-132.

Nishimoto, S., \& Bhushan, B. (2013). Bioinspired self-cleaning surfaces with strong hydrophobicity, superoleophobicity, and superhydrophilicity. RSC Advances, 3, 671-690.

Osborn, D., Hassan, M., Asadi, S., \& White, J. R. (2014). Durability quantification of TiO2 surface coating on concrete and asphalt pavements. Journal of Materials in Civil Engineering, 26, 331-337.

Parkin, I. P., \& Palgrave R. G. (2005). Self-cleaning coatings. Journal of Materials Chemistry, 15, 1689-1695.

Quagliarini, E., Bondioli, F., Goffredo, G. B., Cordoni, C., \& Munafò, P. (2012). Self-cleaning and de-polluting stone surfaces: TiO2 nanoparticles for limestone. Construction and Building Materials, 37, 51-57.

Rigone, P. (2011). Le facciate continue - La manutenzione dell'involucro edilizio vetrato. Sant'Arcangelo di Romagna (RN), Italy: Maggioli Editore. 
Ritter, A. (2007). Smart Materials in Architecture, Interior Architecture and Design. Birkhäuser.

Salthammer, T., \& Fuhrmann, F. (2007). Photocatalytic surface reactions on indoor wall paint. Environmental Science \& Technology, 41, 6573-6578.

Sciancalepore, C., \& Bondioli, F. (2015). Durability of SiO2-TiO2 photocatalytic coatings on ceramic tiles. International Journal of Applied Ceramic Technology, 12, 679-684.

UNI EN 15802:200 (2009). Conservation of cultural property - test methods - Determination of static contact angle.

Watanabe, T., Nakajima, A., Wang, R., Minabe, M., Koizumi, S., Fujishima, A., \& Hashimoto, K. (1999). Photocatalytic activity and photoinduced hydrophilicty of titanium dioxide coated glass. Thin Solid Films, 351, 260-263.

Yang, Y. H., Han, Y. S., \& Choy, J. H. (2006). TiO2 thin-films on polymer substrates and their photocatalytic activity. Thin Solid Films, 495, 266-271. 